\title{
Didactic Strategy for Students to Prepare a Protocol to Conduct a Drug Stability Study
}

\author{
José Ml. Fallas-Ramírez ${ }^{*}$, Lidiette Fonseca-González \\ School of Pharmacy, University of Costa Rica (UCR), the Republic of Costa Rica
}

Received August 6, 2019; Revised September 3, 2019; Accepted September 17, 2019

Copyright $\odot 2019$ by authors, all rights reserved. Authors agree that this article remains permanently open access under the terms of the Creative Commons Attribution License 4.0 International License

\begin{abstract}
The results of a didactic strategy Workshop application in the course of Pharmaceutical Physicochemistry II are presented. This strategy allows building knowledge significantly when establishing a relationship with personal experience. The knowledge and application of the current regulations for the development of drug stability studies in Costa Rica, is a fundamental aspect of the pharmacist's work in this country. For this reason, in this course which is taught in the third year of the pharmacy career at the University of Costa Rica, the topic is included when the issue of drug stability is developed. This activity proposed a new way of approaching the issue, involving the student in the construction of a more meaningful knowledge, by management and application of the stability norms developing along the semester in five stages: 1) plan the strategy, 2) coordination between the teachers of the different laboratory groups, 3) knowledge of the basic concepts of stability by students, 4) application of the teaching strategy in two laboratory sessions and 5) evaluation of the strategy by students, through the Google Forms platform. The work teams reviewed the Central American Technical Regulations (RTCA) and developed the stability protocol for the assigned drugs. Subsequently, they presented their proposals at the indicated time. Conclusion: The strategy used was very successful for the development of the issue of regulatory aspects of drug stability, since it aroused the interest of most students and validates the need to conduct coordination meetings between teachers.
\end{abstract}

Keywords University Teaching, Workshop, New Strategies, Drug Stability

\section{Introduction}

The universities are centers of higher education which have as their final objective, to develop well-informed professionals, with critical thinking, motivated and with the capacity to solve problems and assume social responsibilities [1]. This demands a constant review and transformation of educational systems, in order to face the new nature of education derived from the globalized world of which today's society is a part [2, 3].

In the learning of any discipline, it is important to offer students the spaces for the critical inquiry of concepts, principles, theories and scopes that allow them to create a discourse, knowledge and the necessary awareness in their professional field [4]. Therefore, the new trends in higher education are directed towards a learning process, in which students must be actively involved in their learning. It implies the creation of opportunities that foster mechanisms for the construction of their own knowledge. This implies the action of "learning by doing" and not just sitting passively listening. For this, it is necessary that the teacher tries to propose situations that allow the student dynamism in the class and that facilitates the work on the concepts in different ways, including multisensory activities $[5,6]$.

The didactic strategy known as a workshop is based on carrying out a specific learning activity through the development of manual skills. It is an educational space that allows relating the academic-theoretical knowledge, with the daily life of the students, in order to promote life skills, or in this case, skills for future professional [7]. This strategy allows participants to propose topics about the discourse, exchange opinions, express interests or doubts, fears; as well as the possibility of deciding the moment in which they begin and conclude their interventions; all this without thinking directly about a possible "teacher censorship". In addition, it is a participatory space that allows reducing the hierarchical teacher-student relationship, to which they are accustomed. With this strategy, knowledge can be constructed in a meaningful way, since it allows establishing a relationship between personal experience and knowledge construction. Likewise, the workshops propose the development of pleasant 
activities that allow the resolution of everyday problems, generating a context of knowledge, which is shared and that is supported by the developed sociocultural skills of those who participate. Also, it allows integrating theory with practice, a relationship that in many cases is separated. And finally, it has a systemic character, since it involves a process of planning, systematization of actions and execution of the developed guidelines (which are previously established); as well as the creation of a theoretical-conceptual foundation. For these reasons, it is very useful in the organization of knowledge and the establishment of correlations in the learning process [7-11].

For all the above, it was proposed to carry out an evaluation activity in the form of a workshop, to study the concepts related to the implementation of stability protocols for different pharmaceutical products, in the Pharmaceutical Physicochemistry II course; part of the pharmacy career at the University of Costa Rica, in order to allow the development of orality and highlight the need to articulate the generation of knowledge with practice, as well as to stimulate capacities in the self-construction of knowledge, having the teacher as a guide and not only as a source of contents, in the students' learning process.

\section{Methodological Strategy}

\subsection{Population Selection}

This strategy was implemented with the 72 students of the Pharmaceutical Physicochemistry II course of the pharmacy career of the University of Costa Rica. These were divided into 8 labor groups, which oversaw 5 different teachers.

\subsection{Strategy Planning}

As Figure 1 shows, the strategy was divided into 5 stages for the implementation in the course. The first stage consisted of the activity planning process, including the development of a guide for the workshop sessions; as well as the selection of pharmaceutical products examples, which were the object of stability protocol to be developed during the workshop. The second stage was the coordination with all the teachers involved, in order to explain and train them for the execution of the didactic strategy. The third stage corresponded to the students' conceptualization process, about the necessary thematic contents, for the optimal development of the workshop. This part was done in the theory classes, emphasizing those concepts necessaries for the understanding of the activity to be carried out.

The fourth stage consisted of the development of the workshop, which was divided into two parts (which will be explained below). And finally, the fifth part was the process of evaluation of the didactic strategy, by the students, in order to obtain their impressions about this.

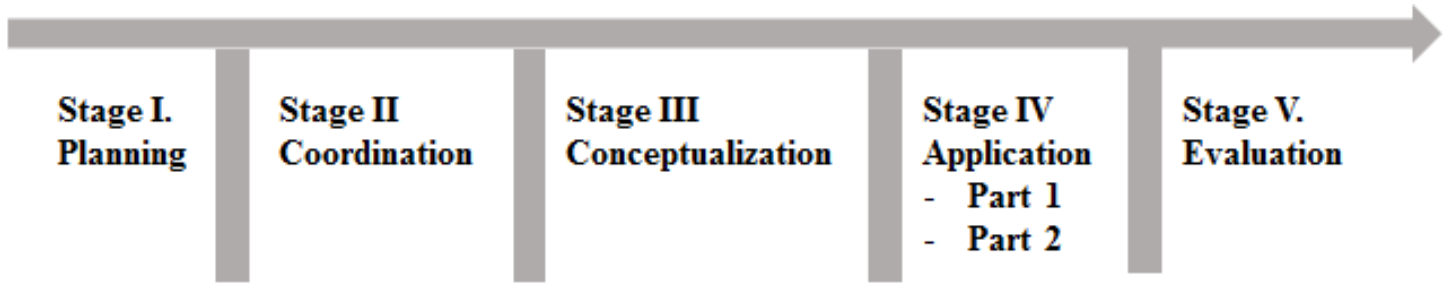

Figure 1. Process of implementation of the didactic strategy. The proposal consisted of five stages developed throughout the semester. Stage I corresponded to the planning of the strategy. Stage II consisted of a coordination process between the professors of the different laboratory groups. Stage II corresponded to the process of acquiring the basic concepts of stability by the students. Stage IV was the application of the didactic strategy in two sessions. Stage V was an evaluation of the strategy by the students, through the Google Forms platform 


\subsection{Workshop Development}

The workshop was divided into two work sessions, which were held at the hours designated for the laboratory in two consecutive weeks. Previously, the students of each laboratory group were divided into subgroups of two or three people and were assigned different pharmaceutical products on which they should perform the stability protocol, according to the Central American Technical Regulations (RTCA) which is the regional reference for the pharmaceutical industries, about this type of protocols.

In the first work session, the students had access to national and international guidelines about conducting stability studies on pharmaceutical products; as well as a written guide detailing all aspects and indications to be considered, to develop the workshop. In addition, they could bring their electronic devices to the workshop for supporting research work and develop the stability protocol. At the end of this session, the groups delivered an initial draft with a proposal of the protocol in Word format, to each teacher in charge of the group. He reviewed them and set a date for a meeting with the students before the second session, in order to review the corrections and work on the presentation of the protocol.

In the second session, the students made an oral presentation (in Power Point format) of the proposals, which lasted 30 minutes (20 minutes to develop the presentation of the proposal and 10 minutes for questions from classmates and the teacher) by subgroup.

\subsection{Strategy Evaluation}

At the end of the second work session, students were allowed to make an evaluation of the didactic activity developed. This was done through the Google Forms platform, which had four questions in liker scale format to evaluate the methodology, organization, self-participation and the teaching guide; from very poor to very good.

Likewise, it had three open questions, which sought to gather information about the learning obtained, aspects that they liked about the strategy and improvement options for future workshops.

Finally, the data were tabulated and plotted for analysis using the Excel tool.

\section{Results}

\subsection{Development of the Activity}

In the first part of the workshop, the students worked on the elaboration of a stability protocol applied to a specific pharmaceutical form (image 1.A). In a group of two or three people, they reviewed the Central American Technical Regulations (RTCA), as well as the international guidelines on drug stability. They prepared a draft of their protocol, which was reviewed and corrected with the help of the laboratory professor in charge. In the second part, the students presented their protocols to the rest of the laboratory partners (image 1.B and 1.C) and discussed the findings, similarities and differences to be considered for the implementation of the stability protocols of the different pharmaceutical products.

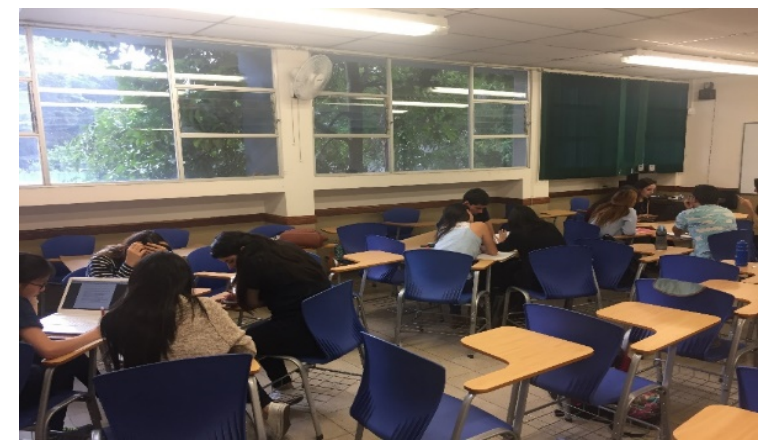

A

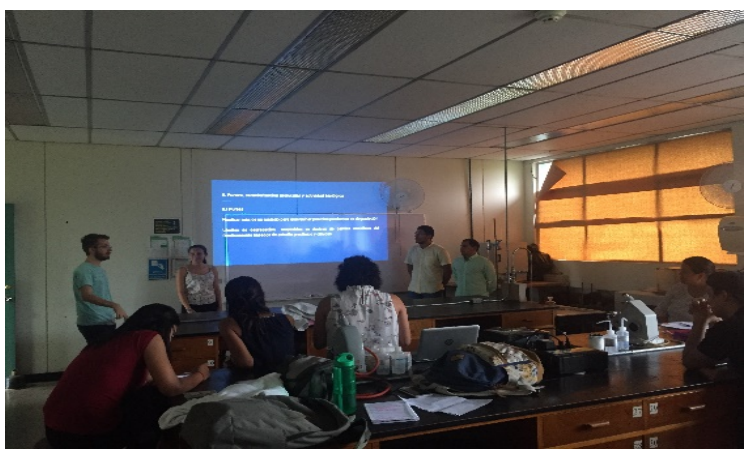

B

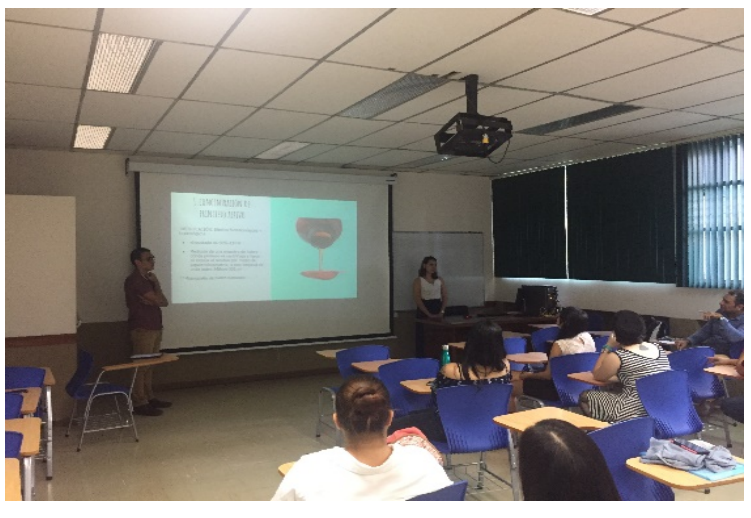

C

Image 1. Photographs of some students of the Pharmaceutical Physicochemistry II course developing the workshop. Image A corresponds to laboratory group 03 performing the first part of the workshop. Images B and C show the students of laboratory groups 05 and 06 (respectively) exposing their protocol

\subsection{Activity Evaluation}

Once the two parts of the workshop were completed, the students carried out an evaluation of the strategy, which contained four questions in Liker scale format and three open questions. The results of Liker scale evaluation are shown in Figure 2. 
A Methodology used to develop the contents

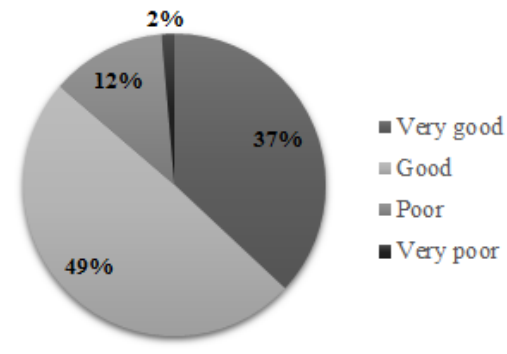

C Participation and self-interest during the workshop

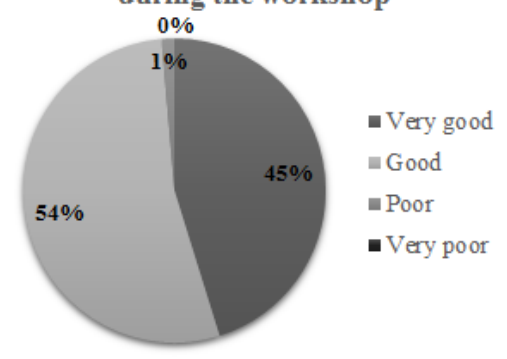

B

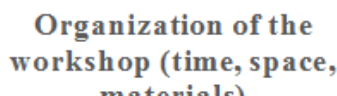
materials)

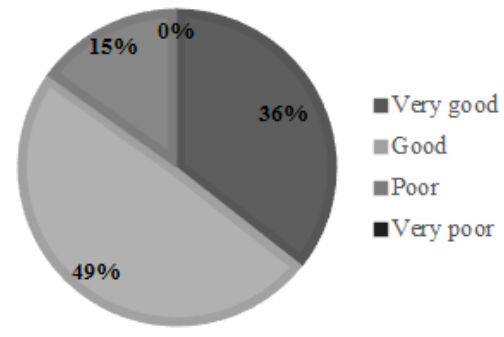

D Teacher's guidlines and interventions during the workshop

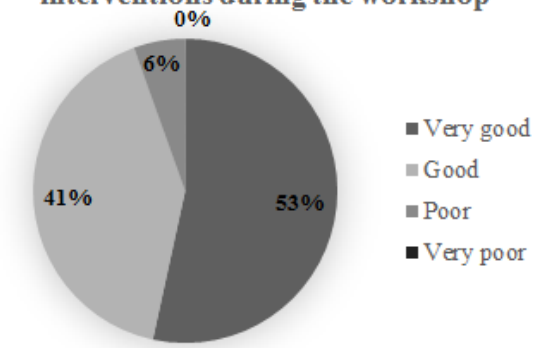

Figure 2. Evaluation of the didactic strategy using a Liker scale. The graphs show the evaluation of the students about the methodology used (A), the organization of the activities (B), their own participation in the workshop (C) and the teacher's guide during the activity (D). In all aspects, it was observed that the students rated the activity as good or very good

One of the aspects evaluated corresponded to the methodology used for the development of the workshop (Figure 2.A). $37 \%$ of the students believe that the methodology was very good and $49 \%$ that it was good, which shows a positive appreciation of the way, in which the subject was approached.

The organization of the activity was also evaluated (Figure 2.B) showing that $36 \%$ of the students considered that it was very good and $49 \%$ that it was good, and as the methodology, indicates that the workshop organization was adequate to meet the objective.

The student's attitude and interest in the strategy were also evaluated (Figure 2.C) and it was observed that 45\% considered that they had a very good participation and $54 \%$ a good participation.

Finally, the teacher's guide in the development of the workshop was evaluated (figure 2.D) and the results show that $53 \%$ of the students considered that the teacher had a very good participation in the activity, while $41 \%$ considered that their guidelines were good.

The analysis of the open questions allowed classifying the recommendations of the students in different categories as shown in table 1 . In the same way, it was possible to identify that the aspect that they liked most about the workshop was the possibility of analyzing in depth the regulations existing in Costa Rica, about drug stability protocols.
Table 1. Analysis of student suggestions to improve the workshop

\begin{tabular}{|l|c|}
\hline $\begin{array}{l}\text { General classification of workshop } \\
\text { improvement opportunities for future } \\
\text { applications of this strategy }\end{array}$ & $\begin{array}{c}\text { Frequency of } \\
\text { suggestions }\end{array}$ \\
\hline $\begin{array}{l}\text { Greater clarity when giving the initial } \\
\text { indications. }\end{array}$ & 21 \\
\hline More time to complete the protocol. & 18 \\
\hline $\begin{array}{l}\text { Have examples of real protocols before the } \\
\text { activity. }\end{array}$ & 16 \\
\hline $\begin{array}{l}\text { Provide previously some model for the delivery } \\
\text { of the protocol proposal at the end of the first } \\
\text { part of the workshop. }\end{array}$ & 14 \\
\hline $\begin{array}{l}\text { Assign with a long time before the } \\
\text { pharmaceutical product to study, to carry out } \\
\text { research prior to the workshop. }\end{array}$ \\
\hline
\end{tabular}

Source: survey of students in the course of Pharmaceutical Physical Chemistry II

\section{Discussion}

This workshop was created as part of a research proposal of the University Didactics course, which is a requirement that teachers of the University of Costa Rica must carry out as teacher training in this university center.

This evaluation proposal had five stages for its development and implementation (figure 1). It began with 
a planning period with the help of the tools studied and the teacher's guide in charge of the didactic course mentioned above. This step is very important for the success of any new strategy, since factors such as resistance to change or lack of experience can hinder the fulfillment of the proposed objectives [12]. In addition, in order to successfully implement this strategy, close coordination with all the teaching actors responsible for the target student was necessary, in order to unify criteria and ensure equity in the development of knowledge in all participants [13]. Likewise, before the development of this innovative educational strategy, it was necessary to ensure that each student had the minimum knowledge required for the understanding and use of the strategy, in order to give dynamism to the development of the proposed activity [14] which was done in theoretical class before the development of the workshop. All the above was a guarantee of success in the implementation of the strategy, however, only by conducting an evaluation at the end of the strategy, it was possible to measure the level of success obtained in the workshop [15].

This was implemented as part of the evaluation of the topic on drug stability, which is part of the agenda of the Pharmaceutical Physicochemistry II course, which is located in the $\mathrm{V}$ cycle of the Pharmacy career of the University of Costa Rica. 72 students enrolled in the course participated in the didactic strategy, which was developed in some of the laboratory sessions (image 1) and in each of the laboratory groups. It is important that part of the success obtained with this activity, depended on the number of students per group, since being such a large group, the management of this could hinder the fulfillment of the goals. Therefore, working in small groups (no more than 12 people in this case) is recommended when new evaluation activities are implemented [16].

The workshop was conducted without complications during the established sessions and in order to measure the level of success of the strategy, it was evaluated by means of a survey, which was completed by all the participating students. Figure 2 shows the results of the closed questions that were asked in order to evaluate aspects such as the methodology used (A), the organization of workshop activities (B), the interest of each student in the activity ( C) and the guidance received by the teachers in charge (D). In all aspects, it was observed that the positive assessment of the student body was greater than $85 \%$, since they believe that these were good or very good. These results allow validating the success of the evaluation activity, which is consistent with other studies, in which the implementation of innovative educational strategies is very well received by university students [17-19].

Finally, through open questions, students' opinions about the strategy in general were collected, in order to detect opportunities for improvement for future workshops. These were analyzed and categorized into 5 groups as shown in table 1 , considering the most relevant aspects in which most participants converged. The most relevant aspects were the establishment of clearer indications (21 students from a total of 72), as well as the time to develop the activity (18 students from a total of 72), which is natural, because it is the first time that pharmacy students face an activity like this. The other aspects included to have preview stability protocols examples and knowing in advance the most relevant aspects of the workshop, which is understandable, because when students are exposed to an unknown topic, they may feel lost and disoriented, which makes them spend more time to start with the activity, organize their ideas, and find a way to develop the tasks that are requested [20].

\section{Conclusions}

This strategy presents a series of benefits, which reinforce the learning process from the constructivist approach. Among these can be cited: the promotion of the horizontal relationship between the teacher and the student, because the work in many cases is jointly between the student participating in the workshop and the teacher who guides it closely. Teamwork is also reinforced rather than a group work, since being an "in situ" investigation and that also required the delivery of a proposal at the end of the activity, the students were in need of working together in real time, avoiding practices "distribution of work" that characterizes the group work that is assigned as extra class tasks. Another positive aspect is the development of critical thinking in students, because when making a protocol for a specific product, the student had to discriminate, analyze and decide on the vital and non-relevant aspects, in the preparation of the protocol of stability. Finally, it is worth highlighting the approach that was achieved between the pharmacy student and an activity of professional practice at an industrial level, when using a real product marketed in the country.

It is important to note that this activity has two primary limitations. The first is the time available to carry it out which was insufficient, since this workshop was the first time the student has such an approach with the regulations on medication stability. A proposal to try to improve this limitation is the development of a more detailed guide that allows the student beforehand, to have a scheme of what is expected of him in this activity; as well as devote more time to the analysis and construction of the protocol. Secondly, it was possible to observe that the limitations in the English language in some students can make it difficult to study and analyze international regulations (which are in this language, because they are official). In this regard, not much can be done directly to address this deficiency; however and as far as possible, it should try to have available to the student, the largest amount of bibliography in the Spanish language (as was the case in this workshop) and note the importance of learning this language for their 
future professional career.

Finally, it is expected that this activity will continue to be developed in the next semesters where the course of Pharmaceutical Physicochemistry II is offered, considering the observations presented in this document.

\section{Acknowledgements}

To Professor Nora Cascante of the Department of University Teaching $(D E D U N)$ of the University of Costa Rica, for her support and guidance during the development and implementation of this didactic strategy.

\section{REFERENCES}

[1] Parra Chacón E, Lago de Vergara D. Didáctica para el desarrollo del pensamiento crítico en estudiantes Universitarios. Educ Médica Super. 2003; 17: 0-0.

[2] Azman N, Che Omar I, Md Yunus AS, Zain ANM. Academic promotion in Malaysian public universities: a critical look at issues and challenges. Oxf Rev Educ. febrero de 2016; 42(1): 71-88.

[3] Barrón Tirado MC. Docencia universitaria y competencias didácticas. Perfiles Educ. 2009; 31: 76-87.

[4] Serrano de Moreno S. El desarrollo de la comprensión crítica en los estudiantes universitarios: Hacia una propuesta didáctica. Educere. 2008; 12: 505-14.

[5] Prieto Navarro L. Aprendizaje activo en el aula universitaria: el caso del aprendizaje basado en problemas. Miscelánea Comillas Rev Cienc Humanas Soc Vol 64 Núm 1242006 ENERO-JUNIO 2006 [Internet]. 2006; Disponible en: http://revistas.upcomillas.es/index.php/miscelaneacomillas /article/view/6558/6367

[6] Ruiz-Gallardo J-R, Castaño S, Gómez-Alday JJ, Valdés A. Assessing student workload in Problem Based Learning: Relationships among teaching method, student workload and achievement. A case study in Natural Sciences. Teach Teach Educ. el 1 de abril de 2011; 27(3):619-27.

[7] Rodriguez Luna ME. Lenguaje y Educación: Perspectivas metodológicas y teóricas para su estudio. Colombia: Universidad Distrital Francisco José de Caldas; 2012. 13-43 $\mathrm{p}$

[8] Concepción IP, Pérez OGB, Camaño Carballo L, González Reyes Y, González Benítez SN. Efectividad de un taller para docentes de diseño de recursos didácticos en el mejoramiento de la calidad de las guías didácticas. Eff Teach Workshop Des Didact Resour Improv Qual Didact Guidel. julio de 2018;32(3):80-93.

[9] Donlevy J. The Regional Partnership of Schools and Colleges at Purchase College, State University of New York: Innovative Strategies for Reaching Higher Academic Standards. Int J Instr Media. diciembre de 1999;26(4):363.

[10] Mendoza Bravo KL, Castellanos Noda AV. El Taller De Capacitación: Un Espacio De Reflexión Y Apropiación
Teórico-Metodológica De Estrategias De Enseñanza En El Contexto Educativo No Formal. Train Workshop SPACE Reflect Theor Methodol Appropr Teach Strateg NON-Form CONTEXT. diciembre de 2016;21(4):86-107.

[11] Urrego Tobón Á. El Taller Como Estrategia Para El Desarrollo De Habilidades, Una Propuesta Para Estudiantes De Licenciatura En Educación Básica. Workshop STRATEGY Dev Ski Propos Stud BASICEDUCATION DEGREE. enero de 2011;7(12):23-34.

[12] Castillo N M. La profesión docente. Rev Médica Chile. julio de 2010;138(7):902-7.

[13] Martínez MJB, Yus MÁM, Currás MP. Coordinación docente e interdisciplinariedad: análisis de su contribución a la adquisición de competencias docentes y discentes. REDU Rev Docencia Univ. el 30 de agosto de 2013; 11(2): 443-62.

[14] Rué J. Cnceptualizar el aprendizaje y la docencia en la Universidadmediante los ETCS. Rev Interuniv Form Profr. 2004; (51):179-96.

[15] LlarenaMG. Metodología para la Evaluación de la Calidad de Estrategia Didácticas de Cursos a Distancia (MACCAD). Form Univ. 2008; 1(2):37-46.

[16] Magnarli G, Quintana MM, García L, De Rosso E, Cabrera L, Ruíz-Moreo L. El trabajo en pequeños grupos facilita La enseñanza-aprendizaje de Bioquímica. Rev Bras Educ Méd. 2009;33(3):374-92.

[17] Carrillo Gullo MA, Ortega Montes JE, Valencia Jiménez NN. Impacto Del Uso De Las Mediaciones Didácticas Interactivas En El Aprendizaje De Los Estudiantes Del Modelo Educativo Transformemos Educando En El Departamento De Córdoba. Impact Using Interact Teach Mediat Learn Stud Educ Model Transform Educ Educ Change Dep Córdoba - Colomb. julio de 2011;19(2):320 39.

[18] Nossa Sánchez J. Efectos Diferenciales De Dos Estrategias Didácticas Sobre El Aprendizaje En Estudiantes Universitarios. Differ Eff Two Didact Strateg Learn Univ Stud. septiembre de 2007;14(2):289-311.

[19] van Wyk MM. Student Teachers' Views Regarding the Usefulness of Reflective Journal Writing as an Eportfolio Alternative Assessment Strategy: An Interpretive Phenomenological Analysis. Gend Behav. octubre de 2017;15(4):10208-102219.

[20] Salinas J. Innovación docente y uso de las TIC en la enseñanza universi aria. RUSC Univ Knowl Soc J. 2004; 1(1):1-16. 